This item was submitted to Loughborough's Research Repository by the author.

Items in Figshare are protected by copyright, with all rights reserved, unless otherwise indicated.

\title{
An evaluation of the economic and business investment impact of an integrated package of public transport improvements funded by a Workplace Parking Levy
}

\section{PLEASE CITE THE PUBLISHED VERSION}

http://dx.doi.org/10.1016/j.tra.2017.04.034

\section{PUBLISHER}

(C) Elsevier

\section{VERSION}

VoR (Version of Record)

\section{PUBLISHER STATEMENT}

This work is made available according to the conditions of the Creative Commons Attribution 4.0 International (CC BY 4.0) licence. Full details of this licence are available at: http://creativecommons.org/licenses/ by/4.0/

\section{LICENCE}

CC BY-NC-ND 4.0

\section{REPOSITORY RECORD}

Dale, Simon, Matthew W. Frost, Stephen G. Ison, Ken Nettleship, and Peter Warren. 2019. "An Evaluation of the Economic and Business Investment Impact of an Integrated Package of Public Transport Improvements Funded by a Workplace Parking Levy". figshare. https://hdl.handle.net/2134/26231. 


\title{
An evaluation of the economic and business investment impact of an integrated package of public transport improvements funded by a Workplace Parking Levy
}

\author{
Simon Dale ${ }^{\mathrm{a}, \mathrm{b}, *}$, Matthew Frost ${ }^{\mathrm{a}}$, Stephen Ison ${ }^{\mathrm{a}}$, Ken Nettleship ${ }^{\mathrm{c}}$, Peter Warren ${ }^{\mathrm{b}}$ \\ ${ }^{a}$ Centre for Innovative and Collaborative Construction Engineering, School of Civil and Building Engineering, Loughborough University, UK \\ ${ }^{\mathrm{b}}$ Nottingham City Council, UK \\ ${ }^{\mathrm{c}}$ Independent Expert on Inward Investment, Previously Nottingham City Council, UK
}

\section{A R T I C L E I N F O}

\section{Article history:}

Received 8 December 2015

Received in revised form 25 July 2016

Accepted 28 April 2017

\section{Keywords:}

Evaluation

Parking

Levy

Workplace

Economic

Inward investment

\begin{abstract}
A B S T R A C T
Hypothecated revenue from the Nottingham Workplace Parking Levy (WPL) is being used to fund additional tram lines, refurbish the Nottingham Railway Station and to sustain the supported Linkbus network. This strategy aims to constrain congestion, cater for future economic growth and make Nottingham a more attractive location for business investment and to live, visit and work.

Literature reveals that the Nottingham WPL forms a relatively small proportion of a business' turnover and that the availability of an efficient public transport system is an important factor in business location decisions. Consequently, central to the WPL package is the expectation that an improved public transport network will prove sufficiently attractive to the business community to offset any perceived negativity of the WPL and hence make Nottingham an attractive business location relative to other UK and European Cities.

This paper aims to evaluate the economic and inward investment impact of the Nottingham WPL package.

The Theory of Change approach is used to analyse the impact complemented by benchmarking against comparator Cities. A range of available indicators are used including economic output, employment, net business VAT registrations, the level of investment enquiries and successes and investment case studies.

The paper concludes that there is strong evidence that the WPL is not having a significantly negative impact on inward investment. Additionally, strong growth in employment and output, combined with a positive movement of inward investment indicators, suggests that Nottingham remains relatively attractive to investors. There is emerging evidence from investment case studies that the public transport improvements are playing a role in this.
\end{abstract}

(C) 2017 Published by Elsevier Ltd. This is an open access article under the CC BY license (http://creativecommons.org/licenses/by/4.0/).

\footnotetext{
* Corresponding author at: Centre for Innovative and Collaborative Construction Engineering, Loughborough University, Loughborough, Leicestershire LE11 3TU, UK.

E-mail address: simon.dale@nottinghamcity.gov.uk (S. Dale).
} 


\section{Introduction}

The Nottingham Workplace Parking Levy Package (WPL Package) is an integrated collection of transport demand management measures aimed at constraining congestion, providing additional sustainable transport capacity to cater for growth and contributing to making Nottingham a more attractive City for business investment. The WPL Package includes the UK's first Workplace Parking Levy (WPL) which, as well as acting as a transport demand management measure, also provides the core funding mechanism for the package which includes a programme of public transport improvements totalling £600 million. The WPL levies a charge on employers who provide more than 10 parking places for their employees, regular business visitors and students. The current charge is $£ 379$ per parking place and the WPL is raising in the region of $£ 8 \mathrm{~m}$ per year. The WPL was introduced in September 2011 although charging did not commence until April 2012.

This paper focuses on evaluating the economic impact of the WPL package with specific reference to its effect on inward investment using a theoretical evaluation framework. This includes a quasi-experimental component which compares data for Nottingham to that of similar UK Cities.

The paper provides a literature review on the link between transport interventions, business location, and wider economic impacts together with the application of theoretical evaluation approaches as they relate to transport interventions.

The research approach and its application to the WPL package evaluation is then explained. As part of this a Theory of Change (ToC) approach is presented which maps the logic of intervention and subsequent change which is intended to lead to the desired economic impact.

The penultimate section presents the research findings and assesses changes to the chosen indicators against the ToC. Finally, the conclusion draws together the research findings providing evidence as to what extent the WPL package is contributing to enhancing Nottingham as a place for business location.

\section{Background}

Nottingham is a medium sized English city, situated $180 \mathrm{~km}$ north of London with a population of 308,000 sitting within a wider conurbation with a total population of 670,000 . The WPL operates within the Nottingham City area, but the benefits of the associated public transport improvements affect the whole conurbation. Nottingham City Council, the Municipal Authority for the City administrative area, has identified the following priorities which their Transport Policies will need to address (NCC, 2015):

1. Congestion: It has been estimated that peak period congestion costs the City economy $£ 160$ million a year (EMDA, 2007) and is particularly acute on key radial routes and the Ring Road.

2. Connectivity: The City Council believes that good connectivity to other urban centres and national and international gateways is essential if Nottingham is to remain competitive as a location to do business.

3. Significant Growth: Using data from the Office for National Statistics, City Council forecasts indicate that its population is set to rise by $9 \%$ over a 15 year period from 2011, resulting from increased job opportunities driven by a growth in science and technology, knowledge intensive and creative industries as well as underlying demographic factors.

The WPL contributes to the above in two ways; firstly to act as a transport demand management measure and secondly to provide the local financial contribution for a package of sustainable transport measures, specifically:

- two additional tram lines;

- the refurbishment of Nottingham Railway Station;

- ongoing support for key bus services connecting important employment and retail locations and hospitals to transport hubs (Known as LinkBus), including conversion of the fleet to electric power;

- support for employers to introduce parking management schemes and workplace travel plans.

The WPL and the transport improvements which it funds are termed the WPL Package and are intended to complement each other and work as an integrated set of measures to contribute to constraining congestion, cater for growth and facilitate connectivity. Thus, one of the key stated objectives for the WPL Package is the economic objective of enhancing the attractiveness of Nottingham as a location for business investment. This objective also addresses one of the main barriers to the implementation of WPL schemes, namely the criticism that, as the WPL liability lies with the employer, it is a business cost and will thus act as an impediment to inward investment (Burchell and Ison, 2012; Nottingham Post, 2012). Evidence in Nottingham to date shows that a significant number of the larger employers have passed the cost on to their employees, thus mitigating the cost on their business, however, medium sized organisations have tended to absorb the cost (Dale et al., 2014).

A study carried out by Price Waterhouse Cooper (PwC) on behalf of Nottingham City Council prior to the introduction of the WPL (NCC, 2005) showed that, although the WPL was likely to be less than $1 \%$ of a business' turnover, businesses were highly critical of having to bear this cost despite the transport improvements this would bring. Sixty percent of businesses interviewed for this study said they would relocate some activities away from Nottingham and more than $50 \%$ said they would reduce planned investment. 66\% felt the WPL would not be offset by improvements in public transport. This identifies 
a contradiction; as there is wealth of literature which shows that a high quality transport system is important to business location (see Section 3) yet businesses react negatively to contributing towards the cost of providing this. Nottingham City Council believes that the overall business location offer will be enhanced by the WPL funded public transport improvements and that this will offset the deterrent effect on investment of the additional cost of WPL (NCC, 2008).

\section{Literature review}

In this section we review literature concerning potential alternative approaches to economic evaluation. In doing so we also examine the conclusions drawn from literature concerning the role transport interventions play with respect to business location and wider economic impacts.

\subsection{A theoretical view of business location}

Arauzo-Carod et al. (2010) citing Hayter (1997) present a useful theoretical frame work for examining industrial location by identifying 3 principal theoretical perspectives which underpin research into this area:

Neo-classical - this assumes that rational actors choose a location based on profit maximisation and cost minimisation. Determinants are thus external to a firm. Transport infrastructure is one such determinant. Weber (1929) and Losch (1954) presented seminal theoretical models based on this neo-classical thinking.

Institutional - These theories acknowledge the relevance of neo-classical determinants but also seek to include factors based on the economic relationships with customers, suppliers and public administration which lead to profit maximisation. Congestion Charging is an example of an institutional factor which is put in place by the public administration. Behavioural - Relates to theories which take into account individual preferences which are internal to a business and may not necessarily be entirely profit maximising or cost minimising choices. Behavioural determinants are problematic to include within empirical studies due to the difficulty of assembling relevant data sets and there is thus a dearth of literature reflecting this. However the research that has studied these determinants show them to be significant, for example, Figueiredo et al. (2002), demonstrate that entrepreneurs are willing to accept higher locational costs in order to stay in the areas in which they already live.

In practice determinants from all 3 theoretical perspectives can be included within a study provided there is sufficient data to quantify them. The next part of this literature review summarises the methods that have been employed to achieve this.

\subsection{Approaches to evaluating the role of transport interventions on business location}

Arauzo-Carod et al. (2010) identify two predominant approaches that have been deployed for evaluating the reasons for industrial location, Discrete Choice Models (DCM) and Count Data Models (CDM). The DCM approach analyses data on individual location decisions determined from a fixed set of alternatives, while for CDM the unit of study is at geographical area level rather than at a firm level and requires a count of business locations in any given area. Bhat et al. (2014) used a CDM technique incorporating neo-classical and institutional determinants to demonstrate that transport infrastructure provision was statistically significant in determining the level of firms locating to different areas of Texas.

While these approaches provide consensus that agglomeration economies, transport infrastructure, market size, wages and taxes are significant to business location no such consensus as to the dominant location factors emerge despite numerous examples of this kind of research. Button et al. (1995) suggests that firms adopt 'satisficing policies' whereby provided that the transport infrastructure is seen as sufficient, then other factors not all of which lead to profit maximisation will determine the location choice. These include the preferences of existing staff, social amenities and a general image of a city as a place to live and work. This conclusion is supported by surveys of businesses conducted in the UK (Smyth et al. (2010), (Core Cities et al., 2006). Button (2010) argues that given these less quantifiable factors, the role played by transport can become almost impossible to define by empirical methods. If the presence of behavioural factors is accepted then this could explain the heterogeneity seen in the conclusions from empirical studies.

\subsection{Approaches to evaluating the economic impact of transport interventions}

The two main approaches are microeconomic; Cost Benefit Analysis (CBA) of individual interventions or Macroeconomic models which aim to capture the wider economic impacts of transport infrastructure (Lakshmanan, 2011). The congestion charging schemes in London and Stockholm have utilised CBA in order to evaluate their economic impact. Eliasson (2009) used a CBA to demonstrate that, in Stockholm, the social surplus exceeds the implementation and operating costs. The evaluation of the London Congestion Charge also included a CBA (Leape, 2006) and (TfL, 2008). This demonstrated that there was a social surplus, despite the considerable costs of implementing the scheme. Neither the London nor Stockholm CBAs captured wider economic benefits of the interventions. Transport for London addressed this by a quasi-experimental approach which compares key indicators between areas of London inside and outside the charging area (TfL, 2008). Within this 
approach there is a discussion of major exogenous contextual changes during the evaluation period however the presence of, otherwise similar comparator areas, are assumed to have allowed for this. The evaluation concluded that there has been no detectable negative economic impact from the scheme (TfL, 2008). Anderstig et al. (2016) studied the wider economic benefits of the Stockholm Scheme. They use an estimated relationship between accessibility and income and demonstrate that effects on labour income are positive when value of time heterogeneity between different wage levels is included in the model. Evaluation of the Perth Parking Space Levy, the scheme used as a model for the Nottingham WPL has used a simpler monitoring approach concentrating on employment levels and retail floor space and concludes that as these have continued to grow and that the scheme has had no negative economic impact (Richardson, 2010).

Macro-economic approaches concentrate on modelling impacts brought about by mainly neo-classical mechanisms; agglomeration, labour productivity gains and general equilibrium effects (Graham, 2007; Combes et al., 2008). For example Hensher et al. (2012) combine two existing macroeconomic models in the Sydney region to predict the expected broader economic benefits of the Northwest Rail Link project. They identify $18 \%$ further economic benefit than that shown by a traditional CBA analysis arising from redistribution of employment activities together with gains in labour productivity linked to agglomeration effects.

Lakshmanan (2011) argues that these macroeconomic approaches ignore forward linkages as the impact continues to 'ripple' through the wider economy as time passes. Banister and Thurstain-Goodwin (2011) point out that statistical models which attempt to link transport interventions to macro-economic changes have two major drawbacks firstly that they often fail to take into account contextual factors and secondly that statistical correlation does not necessarily equal causality. Venables (2016) also recognises these forward linkages leading to land use change over time in response to improved transport. Venables suggests a more modular approach whereby individual mechanisms are studied empirically. Quddus et al. (2007) provide an example of such a study. They utilised time series analyses to study the impact of the introduction of the London Congestion Charge (LCC) on retail sales in London. They concluded that overall retail sales were not impacted by the LCC despite some localised negative impacts.

\subsection{Theoretical evaluation approaches}

More recently Theoretical Evaluation approaches have been recommended by the UK DfT in their guidance for the fuller evaluation of major transport schemes in order to provide a more flexible evaluation framework capable of incorporating empirical and qualitative evidence into an evaluation (DfT, 2013). These approaches provide a framework for understanding, systematically testing and refining the assumed connections between an intervention and the anticipated impacts. This takes into account contextual changes, as and when they occur, by incorporating them into the theory (Blamey and Mackenzie, 2007). Theoretical evaluation approaches also aim to demonstrate the attribution of the observed change of indicators to the intervention in question. This consideration of both context and causal attribution allows these approaches to potentially address the key criticisms made by Banister and Thurstain-Goodwin (2011) and Lakshmanan (2011) related to empirical micro and macroeconomic approaches.

The Theory of Change ( $\mathrm{ToC}$ ) approach to theoretical evaluation seeks to describe how an intervention is intended to meet its objective by identifying the logical flow of events that it is assumed will enable this to be achieved (HM Treasury, 2011). Thus, a Theory of Change is articulated by examining the existing evidence base and a debate between stakeholders leading to a consensus on the logic of the intervention. This is often expressed as a logic diagram containing five sequential steps (Blamey and Mackenzie, 2005; DfT, 2013):

- Context/setting - the problem the action will attempt to mitigate and also any relevant contextual factors.

- Inputs - the nature of the intervention and the resources required to implement it.

- Outputs - what those resources deliver on the ground, e.g. a new tram line.

- Outcomes - the effect of the intervention in the short and medium term.

- Impacts - longer term strategic changes which the intervention has effected or contributed to.

This approach will therefore inherently consider forward linkages between a transport intervention and the wider economy over time as proposed by Lakshmanan (2011). A ToC must be tested against a set of indicators to see if they change in the direction and magnitude suggested by the theory. Within this process a broad consideration of the effect of contextual factors is included. Connell and Kubisch (1998) identify four conditions which, if satisfied, would be sufficient to demonstrate attribution of the observed changes to the intervention in question according to the ToC approach:

- The theory is plausible.

- The intervention was implemented as expected.

- The magnitude of the outcomes following the above was as predicted by the theory.

- The absence of any contextual shift that could account for the above outcomes.

Realistic Evaluation (RE) is another method of theoretical evaluation and has many similarities with ToC, but it differs in the level of specificity with which it itemises the causal logic (Blamey and Mackenzie, 2007). Realistic evaluation aims to link a mechanism of change to contextual factors to identify an outcome, i.e. Mechanism + Context $=$ Outcome (Pawson and 
Tilley, 1997). For example, a ToC may link the introduction of a WPL to the outcome of a decreased demand for travel to work by private car and it would satisfy itself with the assertion that this is accepted wisdom. However, a realist evaluator would want to specifically identify the mechanisms which enable this outcome e.g. an increased cost to individuals for parking at work as employers pass on the cost of the WPL to their workforce via parking management schemes. This would then be placed in the light of context, for example, whether or not there is any free on street parking nearby or whether the economic situation is such that the workforce is enjoying a healthy wage rise thus obviating the increased cost of parking. Thus the method is sufficiently flexible to include neo-classical macroeconomic mechanisms by which improved transport infrastructure impact the economy such as agglomeration and labour supply effects (Hensher et al., 2012) as well numerous micro economic enabling mechanisms. Importantly this allows for the inclusion of less quantifiable behavioural determinants proposed by Figueiredo et al. (2002) within the Theory. Even if their presence cannot be proven empirically it is useful to be aware of when and how they can be activated and to seek qualitative evidence to support this. The principle drawback of $\mathrm{RE}$ is that the number of mechanisms and contexts for a large intervention may be so numerous that the approach becomes impractical (Pawson and Tilley, 2004). The possibility of co-existence of the two approaches is acknowledged by Blamey and Mackenzie (2007), indeed they go on to conclude that this may be desirable with ToC providing the overall evaluation framework while RE is used to drill down into the detail of change. This fusion of RE within a ToC framework is not dissimilar to the modular, context specific approach suggested by Venables (2016) whereby economic impact is assessed by empirical evaluation of the known mechanisms by which transport interventions impact the wider economy.

\subsection{Literature review: summary of findings}

In summary, there is a lack of detailed data available for Nottingham to support the application of empirical approaches discussed in Section 3.2 which examine the causality of neo classical and institutional location determinants (including transport interventions) to business location decisions. Furthermore such approaches seldom include behavioural determinants which have been shown to be important in business location decisions. An alternative is presented in Section 3.3 which instead of examining business location uses micro economic CBA or macroeconomic approaches which link transport interventions to economic benefits in the wider economy. The assumption is thus that an ability to attract inward investment would be an essential ingredient for realising these economic benefits. While CBA has been used to examine expost monetarised benefit of transport interventions, the Nottingham WPL business case stressed the importance of the expected wider economic benefits of the WPL package thus a CBA would not be appropriate for this research. While macroeconomic approaches seek to include these wider economic benefits they have a limited ability to take into account forward linkages in the economy over time and limitations with respect to the consideration of contextual factors and causality beyond statistical correlation.

Given the practical consideration of data availability coupled with limitations of the approaches outlined in Sections 3.2 and 3.3 an evaluation frame work based on a ToC as presented in Section 3.4 would provide a more flexible approach capable of incorporating empirical and qualitative evidence. The literature reviewed above suggests that this approach could take into account temporal contextual changes and provide a means of attributing observed change to the elements of the WPL Package. These advantages have led to Theoretical Evaluation approaches being recommended by both the UK DfT (and the UK Treasury in guidance for the evaluation of major transport schemes (DfT, 2013; HM Treasury, 2011). A ToC approach incorporating elements of RE has therefore been chosen to facilitate this research.

\section{Method}

As discussed above in Section 3.5 it was determined that the evaluation of the WPL package including its economic impacts should be based around ToC framework which also identifies the principal mechanisms of change. It should also draw on other approaches including importantly a quasi-experimental element. While a more empirical approach may appear attractive for individual interventions such as NET Phase 2, the lack of data, the scale and diversity of the WPL Package along with the extended time period over which it will be implemented means any evaluation approach must be sufficiently flexible to allow for the use of multiple imperfect evidence sources and be able to take into account both temporal contextual changes and achieve attribution of cause and effect. Tables 1 and 2 present relevant contextual factors and mechanisms of change that have been identified. Fig. 1 incorporates both the mechanisms and contextual factors into a logic map which illustrates the proposed ToC.

This ToC is based on the above literature review, The 2008 WPL Business Case (NCC, 2008) and stakeholder input. This approach includes elements of RE in order to strengthen the ToC. In order to test the ToC, a wide basket of indicators are required including at least one of which provides attribution of observed changes in the indicators to the WPL Package. This is because there is no single economic indicator available that can definitively demonstrate that the WPL package has achieved its economic objective. However, the indicators can be triangulated against each other and, if the majority of indicators move in the direction suggested by the ToC and cross validate one another, then it should be possible to draw a balance of probability conclusion. 
Table 1

Contextual factors that could impact on the economic objective.

\begin{tabular}{|c|c|c|}
\hline & Context & Description \\
\hline C1 & Socio-economic characteristics of Nottingham & $\begin{array}{l}\text { Nottingham is a medium sized English City with a population of } 308,000 \text { ( } 670,000 \text { in the } \\
\text { whole conurbation) (Dale et al., 2014) It ranks } 20 \text { th out of } 326 \text { Local Authority areas for } \\
\text { deprivation and contains pockets of high deprivation. 90\% of its Gross Value Added (GVA) } \\
\text { is accounted for by the service sector (NCC, 2015) }\end{array}$ \\
\hline $\mathrm{C} 2$ & National Economic Conditions & $\begin{array}{l}\text { Most macro-economic indicators show that the WPL package is being implemented in a } \\
\text { period when the national economy is emerging from recession }\end{array}$ \\
\hline $\mathrm{C} 3$ & The Nottingham Offer & $\begin{array}{l}\text { Key operational costs are lower in Nottingham than other comparable Cities in the UK, } \\
\text { with office costs being at } £ 19.00 \text { per sq. ft. for Grade A office space (compared to } £ 35- \\
40.00 \text { in Birmingham and Manchester, } £ 30.00 \text { in Leeds, } £ 25.00 \text { in Milton Keynes and } \\
£ 25.00 \text { in Cardiff) and salary costs on average } 10 \% \text { lower than the national average } \\
\text { (Lambert Smith Hampton, 2014) - these are the main costs that a business will focus on } \\
\text { when deciding on a new location and are key in terms of what Nottingham has to offer as } \\
\text { a location }\end{array}$ \\
\hline C4 & Existing Congestion Problem & $\begin{array}{l}\text { Nottingham City Council estimates that congestion, mainly in the AM and PM peak } \\
\text { period, costs the City’s economy } £ 160 \mathrm{~m} \text { pa (EMDA, 2007). This will manifest as a cost to } \\
\text { business in lost time, increased transport costs, difficulties in access for qualified } \\
\text { workforce, etc. }\end{array}$ \\
\hline C5 & Presumption of Growth & Population projected to grow by $9 \%$ 2011-2026 (NCC, 2015) \\
\hline C6 & $\begin{array}{l}\text { Lack of existing public transport capacity to meet } \\
\text { demand for travel generated by growth }\end{array}$ & $\begin{array}{l}\text { Congestion levels currently show roads at capacity at key junctions. Extra capacity must } \\
\text { be provided by achieving mode switch and providing extra PT capacity to cater for that }\end{array}$ \\
\hline $\mathrm{C7}$ & Availability of Commercial Premises & $\begin{array}{l}\text { Currently there is a chronic shortage of large high quality commercial premises in } \\
\text { Nottingham while rental values are not high enough to stimulate new build }\end{array}$ \\
\hline
\end{tabular}

Table 2

Mechanisms for change to achieve the economic objective.

\begin{tabular}{ll}
\hline & Mechanism \\
\hline M1 & WPL raises hypothecated revenue for public transport improvements \\
M2 & Hypothecated revenue part funds major public transport improvements, for every $£$ 1 the WPL raises it brings in $£ 3$ of UK Government funding \\
M3 & Combination of increased cost of parking at or close to work and better PT options decreases demand for commuting by car \\
M4 & Less need for employers to provide parking. Improved PT reduces the need for employers to provide car parking places thus reducing the \\
& potential cost of a site \\
M5 & Employers provide less parking in order to reduce their WPL liability \\
M6 & Modern public transport system enhances Nottingham's image as a modern City thus making it more attractive as a business location \\
M7 & Employers introduce parking management schemes which pass on the cost of WPL to their employees \\
M8 & Increased PT capacity/efficiency makes Nottingham more attractive as a business location due to improved access to labour and customers \\
& leading to agglomeration economies, increased labour productivity \\
M9 & Transport Demand Management effect of the WPL package reduces cost of congestion to businesses making Nottingham more attractive as a \\
& business location \\
M10 & $\begin{array}{l}\text { Parking management schemes pass burden of WPL to employees, WPL becomes cost neutral for employers } \\
\text { M11 }\end{array}$ \\
& Increase in cost of operating a business in Nottingham. The WPL charge is absorbed by employers thus placing an additional cost burden on \\
M12 & Agglomeration economies associated with quicker journey times and reduced production costs \\
M13 & Labour Force Effects - shorter commutes leads to an increase in quantity and quality of labour and associated productivity improvements \\
M14 & General Equilibrium Effects - improved access to jobs for existing labour force \\
M15 & Reduced production Costs - Time savings from congestion constraint reduce the costs of production \\
\hline
\end{tabular}

In order to strengthen this approach four comparator Cities; Leicester, Liverpool, Newcastle upon Tyne and Sheffield, have been chosen to benchmark macroeconomic indicators. These were chosen based on their geographic and socio-economic similarities with Nottingham.

The indicators can be roughly divided into high level macro-economic indicators and more specific local indicators which track inward investment.

\subsection{Macro-economic indicators}

There are 3 macro-economic indicators; jobs located in Nottingham, economic output and business births and deaths. All three are high level indicators of an area's economic health and as the data is available nationally by Local Authority Area it is possible to benchmark against the four chosen comparator Cities. While a better performance than those comparator Cities would be expected given the proposed ToC, such a performance is not necessarily attributable to the WPL Package without further evidence, because of the contextual differences between the Cities. 


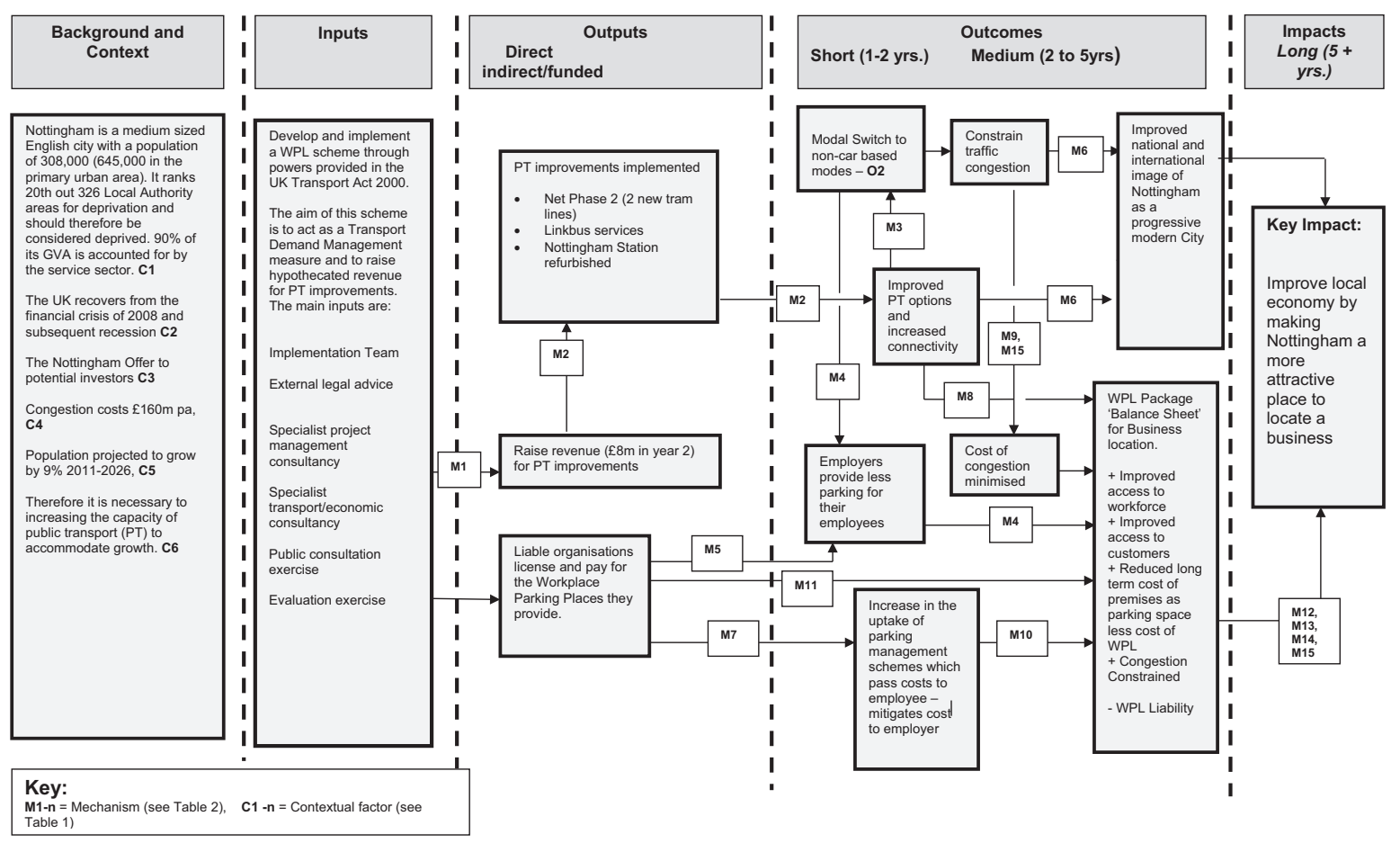

Fig. 1. Logic map for workplace parking levy scheme objective 5; Enhance the attractiveness of Nottingham as a location for business investment.

\subsubsection{Employment levels in Nottingham}

The number of jobs generated within Nottingham City is reflective of the amount of investment that employers make in the City area. Hence, this is a key economic indicator for this evaluation and a differential rise when compared to the comparator Cities would be expected given the proposed ToC. The data for 2008 to 2013 are supplied by the Office for National Statistics (ONS).

\subsubsection{Economic output}

Gross Value Added (GVA) is the normal indicator for tracking regional economic output. The data is available from the ONS by Local Authority Area. A rise in GVA is indicative of a growing local economy and while not the only cause, a healthy level of inward investment is often the driver of such growth.

\subsubsection{Business births and deaths}

The ONS compiles records of business registrations and de-registrations based on VAT records. The data is available by Local Authority Area and nationally and is contained in an annually produced dataset, the latest of which is "ONS Business Demography 2014".

However, for monitoring the effect of the WPL, this data is of limited value, because only a small proportion of the total business population is liable to pay the WPL. This data does not differentiate business size, either in terms of the number of parking places, or employees. Therefore, a change in the number of VAT registered businesses cannot necessarily be linked to the WPL. The churn in smaller businesses is much larger than that of larger WPL liable businesses, thus change in these small non WPL liable businesses is likely to mask any WPL related trends. However, this indicator is still useful as a measure of the economic health of the City. If the ToC is correct one would expect that it should at least keep pace with the comparator Cities, all contextual factors being equal.

\subsection{Specific indicators of levels of inward investment}

The three macro-economic indicators provide an overview of the economic health of the City and as benchmarking data is readily available, Nottingham can be compared to other similar Cities. However, in view of the often cited criticism of WPLs, i.e. that they could damage inward investment, it is important to consider inward investment specific indicators.

- Level of inward investment enquiries to the Municipal Authority

- Level of activity in the commercial property market in Nottingham

- Case studies of inward investment and de-investment decisions 
The case study data is particularly important as this is the main indicator that provides attribution between the WPL package and the other economic indicators.

\subsubsection{Level of inward investment enquiries}

Nottingham City Council (NCC) has an internal team dedicated to working with employers interested in investing in Nottingham. This Inward Investment Team maintains a record of the level of enquiries which they receive and the number of those which end with successful inward investment. Tracking this data year on year will be indicative of the level of investment in the City. This data is limited to those investors that choose to contact NCC and thus this indicator must be assessed against the other indicators as the percentage sample of the total population is unknown and sample bias cannot be ruled out.

\subsubsection{Level of activity in the commercial property market}

A healthy commercial property sector is symptomatic of a buoyant inward investment landscape. Commercial property market activity measured by the volume of agreements completed on commercial property rental has been chosen to evaluate this. In general, the higher the volume of new rental agreements, the more positive for the economic objective. Thus, a rise in the volume of new rental agreements would support the ToC. However, this may not occur continuously as it is constrained by the quantity and size of the stock of commercial premises (C7 see Table 1). An under supply of commercial premises would constrain the indicator. The data is supplied by commercial estate agents via the Nottingham Office Review (Lambert Smith Hampton, 2014).

\subsubsection{Examples of inward investment and de-investment decisions}

These examples explore the reasoning behind important investment or de-investment decisions that have been managed by the City Council's Inward Investment Team. It gives an understanding of the causal factors which influence these decisions, including the role played by improving public transport options and the WPL. The purpose of this indicator is not to quantify the number of investment and dis-investment decisions (which is more comprehensively covered by the other indicators), but rather to provide evidence as to whether the changes observed in those indicators are attributable to the WPL package. The examples have been compiled based on the accounts of Nottingham City Council officers responsible for handling each relevant 'account' and are based on their experience and opinion rather than specific data supplied by the businesses themselves. The officers were responsible for negotiating and assisting each investor or dis-investor and were asked to comment as to whether the WPL or enhanced public transport was a minor or major factor in the investment decision. The reporting officers were also asked their views on the reasoning behind the decision. It is necessary to anonymise the examples for reasons of commercial confidentiality.

Major investments and disinvestments are relatively infrequent, thus there are only 10 examples known to Nottingham City Council since 2013. However, it is likely that this does represent the majority of all such decisions made by larger employers.

\section{Findings}

\subsection{Macro-economic data}

\subsubsection{Jobs located in Nottingham}

Table 3 and Fig. 2 present a time series of data showing the number of jobs in Nottingham and the comparator Cities. The number of jobs in Nottingham increased by 7.5\% between September 2010 and September 2013, which compares favourably with the situation in all four comparator Cities and England as a whole. This indicator has been cross validated against employment rates in the Cities.

Table 4 shows that the employment rate data broadly agrees with the jobs data with Nottingham seeing the highest rate of growth since 2010/11. This data also, however, reveals that Nottingham's employment rate was hit harder by the recession than the other comparator Cities, dropping by $8.2 \%$ between $2008 / 9$ and $2010 / 11$. That said it has since rebounded to a

Table 3

Number of jobs located in Nottingham and comparator cities. Source: Nottingham City Council (NCC) from the Office for National Statistics (ONS) 2014.

\begin{tabular}{llllllll}
\hline \multirow{2}{*}{ City } & \multicolumn{2}{l}{ Number of employees based in City administrational area } & \multicolumn{2}{c}{ \%Change 2010-13 } & \multicolumn{2}{c}{ \%change 2012-13 } \\
\cline { 2 - 6 } & 2008 & 2009 & 2010 & 2011 & 2012 & $2013^{\text {a }}$ \\
\hline Leicester & 158,100 & 156,300 & 158,600 & 154,700 & 154,700 & 158,500 & -0.1 \\
Liverpool & 228,700 & 228,600 & 222,500 & 228,600 & 226,700 & 227,200 & 2.1 \\
Newcastle & 179,600 & 169,000 & 169,000 & 172,800 & 175,900 & 174,300 & 3.2 \\
Nottingham & $\mathbf{1 8 4 , 5 0 0}$ & $\mathbf{1 8 8 , 5 0 0}$ & $\mathbf{1 9 3 , 9 0 0}$ & $\mathbf{1 9 4 , 0 0 0}$ & $\mathbf{2 0 2 , 0 0 0}$ & $\mathbf{2 0 8 , 5 0 0}$ & $\mathbf{7 . 5}$ \\
Sheffield & 250,900 & 243,500 & 240,300 & 237,300 & 239,100 & 240,700 & 0.2 \\
\hline
\end{tabular}

a Provisional. 


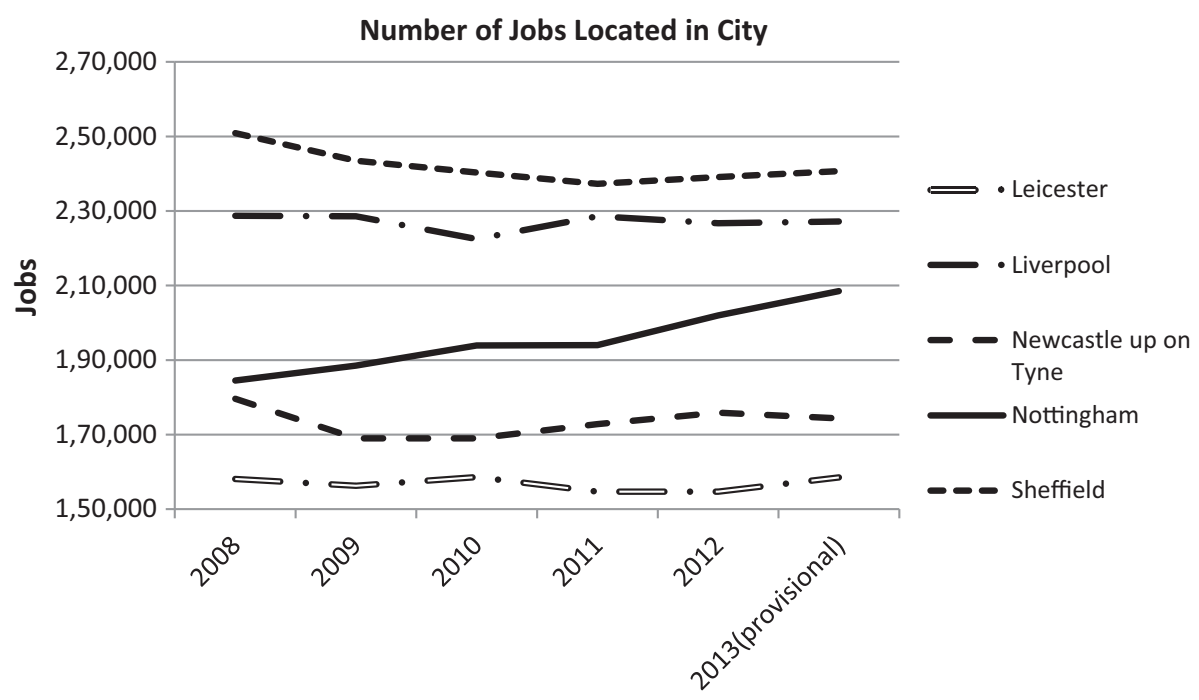

Fig. 2. Numbers of jobs located in Nottingham and comparator cities.. Source: NCC from the ONS 2014.

Table 4

Percentage employment rates in Nottingham and Comparator Cities. Source: NCC from the ONS, 2014.

\begin{tabular}{llllll}
\hline Year & Leicester & Liverpool & Nottingham & Newcastle & Sheffield \\
\hline $2007 / 8$ & 65.7 & 63.5 & $\mathbf{6 0 . 9}$ & 63.2 & 69.4 \\
$2008 / 9$ & 62.8 & 57.7 & $\mathbf{6 1 . 8}$ & 59.5 & 59.9 \\
$2009 / 10$ & 62.0 & 60.2 & $\mathbf{5 6 . 8}$ & 64.3 & 65.7 \\
$2010 / 11$ & 61.7 & 59.8 & $\mathbf{5 3 . 6}$ & 60.8 & 60.4 \\
$2011 / 12$ & 62.0 & 59.6 & $\mathbf{5 9 . 6}$ & 60.6 & 69.0 \\
$2012 / 13$ & 61.9 & 60.0 & $\mathbf{5 9 . 1}$ & 69.0 \\
$2013 / 14$ & 61.2 & 61.2 & $\mathbf{6 0 . 3}$ & & 2.6 \\
\% change 2010/11 to 2013/14 & -0.5 & 1.4 & $\mathbf{6 . 7}$ & & \\
\hline
\end{tabular}

level fractionally below that in $2007 / 8$. Only Sheffield has managed a similar performance while the other comparator Cities are still significantly below their $2007 / 8$ levels. This data shows a positive differential growth in jobs compared to the comparator Cities and thus supports the ToC.

\subsubsection{Economic output}

Table 5 shows that economic output increased in Nottingham at a faster rate between 2010 and 2012 than the average for the four comparator Cities. However, the provisional data for 2013 shows that GVA reduced slightly in Nottingham. This is considered an odd outcome as it contradicts both the local and comparator time series.

It also contradicts the increase in jobs and employment, although it does not necessarily follow that if employment rises then so must GVA - it would depend on the nature of that employment. Until the 2013 data is finalised it would seem prudent to treat it with caution. It is important to wait and see if the 2013 provisional figure is confirmed prior to drawing a conclusion as to whether or not this indicator is supportive of the ToC.

\subsubsection{Business births and deaths}

Table 6 presents a time series showing the percentage change in the balance of businesses VAT registered in each calendar year. In 2010 all Cities experienced a similar level of net loss. However, in 2011 only Nottingham City and Sheffield were still

Table 5

GVA in Nottingham, Comparator Cities and England. Source: ONS 2014.

\begin{tabular}{llllllll}
\hline City & 2008 & 2009 & 2010 & 2011 & 2012 & 2013 (provisional) & \% Change 2010-13 \\
\hline Leicester & 6044 & 6013 & 6194 & 6368 & 6552 & 6873 & 11.0 \\
Liverpool & 9630 & 10,620 & 10,532 & 10,427 & 10,512 & 10,646 & 1.1 \\
Nottingham & 7900 & 7953 & 8402 & 8633 & 8774 & 8726 & 3.9 \\
Sheffield & 9899 & 10,150 & 10,529 & 10,506 & 10,922 & 11,199 & 6.4 \\
Tyneside & 15,511 & 14,877 & 15,509 & 16,657 & 16,650 & 17,181 & 10.8 \\
\hline
\end{tabular}


Table 6

Percentage change in VAT registered businesses for Nottingham, Greater Nottingham and Comparator Cities. Source: ONS Business Demography and NCC, Nov 2014.

\begin{tabular}{|c|c|c|c|c|c|c|}
\hline City & 2008 & 2009 & 2010 & 2011 & 2012 & 2013 \\
\hline Leicester & 2 & -2.6 & -2.4 & 2.1 & 1.1 & 7.4 \\
\hline Liverpool & 2.8 & -2.9 & -1.7 & 0.4 & 0.3 & 7.5 \\
\hline Newcastle & 3.2 & -1.9 & -1.1 & 1.8 & 1.1 & 5.0 \\
\hline Nottingham City & 0.9 & -2.4 & -2.0 & -0.1 & 0.2 & 4.9 \\
\hline Greater Nottingham & 1.2 & -2.5 & -1.7 & 0.2 & -0.4 & 4.2 \\
\hline Sheffield & -0.7 & -3.4 & -2.7 & -1.1 & -1.2 & 2.6 \\
\hline
\end{tabular}

experiencing a small net loss, subsequent data for 2012 shows that Nottingham has returned to a situation of net growth. Nottingham City would, therefore, appear to be "rebounding" more slowly than the surrounding areas and most of the comparator Cities, following a significant slump in 2009 when the whole of the UK was in recession. However, this conflicts with the data for employment which shows Nottingham recovering, if anything, faster than the other comparator Cities.

Additionally, it should be noted that Nottingham City shows a relatively strong performance in 2012 and 2013 compared with Greater Nottingham suggesting growth has been concentrated in the City area. According to the ToC a modest rise in enterprise growth would be expected which at least tracked that of the comparator Cities. At present the performance falls short of this, but it is noted, as explained above, that this indicator may not be directly related to the WPL package.

\subsubsection{Synthesis for macro-economic indicators}

Nottingham shows a relatively strong performance in terms of job creation when compared to the comparator Cities while the situation concerning economic output and new business creation is more ambiguous. As noted above the Business Births and Deaths may not be a direct indicator for the WPL package due to the propensity for the data to be skewed towards small businesses which do not pay the WPL. Economic output is also subject to many opaque contextual factors.

\subsection{Inward investment indicators}

\subsubsection{Commercial property market activity}

Table 7 shows the commercial property market activity in Nottingham from 2011 to 2013.

This shows that the number of new rental agreements was similar in 2011 and 2012, but they have risen in 2013. However, the total floor space involved in those agreements has declined since 2011. The increase in the number of new rental agreements reflects activity in the market by small and medium sized enterprises (SMEs). A growing important contextual factor for this indicator is a scarcity in the supply of good quality large properties and this has driven down the floor space involved overall in the last two years. This reflects that the larger indigenous businesses are in general staying in place. Overall, it is concluded that this indicator, given the context of an under supply of large commercial premises is tracking in accordance with the ToC and is, therefore, indicative of good progress towards the economic objectives of the WPL package.

\subsubsection{Level of inward investment enquiries to Nottingham City Council}

Table 8 tracks the level of enquiries and subsequent successes since 2008/9. There is no evidence to suggest that the level of either inward investment enquiries or successes has fallen since the introduction of the WPL in 2011/12. Indeed, while one must be cautious in the absence of any counter factual data or meaningful benchmarking, it appears that 2012/13 and $2013 / 14$ were the strongest years since $2008 / 9$ for attracting inward investment.

While this must be viewed in the context of a national economy emerging from recession and thus one would expect to see resurgence in inward investment, the magnitude of the increase from 2011/12 seems disproportionate suggesting additional mechanisms may be active.

Additionally, the percentage of enquiries which go on to become an actual investment have increased from 2010/11 perhaps showing that Nottingham is becoming a more competitive location.

This indicator suggests good progress towards achieving this objective and agrees with the ToC. However, in order to attribute this to the WPL package it will be necessary to examine the case study data concerning investment and disinvestment decisions.

Table 7

Commercial property market activity in Nottingham. Source: Nottingham Office Review 2014.

\begin{tabular}{lll}
\hline Floor space Sq. ft. & Year & Number of agreements completed on rental of commercial property \\
\hline 251,768 & 2011 & 42 \\
241,900 & 2012 & 43 \\
190,789 & 2013 & 50 \\
\hline
\end{tabular}


Table 8

Enquiries to the inward investment team and subsequent successes. Source: NCC, Nov. 2014.

\begin{tabular}{llll}
\hline Year & Enquiries & No. of successes & \% Successes \\
\hline $2008 / 9$ & 91 & 3 & 3.3 \\
$2009 / 10$ & 156 & 5 & 3.2 \\
$2010 / 11$ & 110 & 2 & 1.8 \\
$2011 / 12$ & 146 & 5 & 3.4 \\
$2012 / 13$ & 175 & 8 & 4.6 \\
$2013 / 14$ & 176 & 15 & 65 \\
8.5 & 301
\end{tabular}

\subsubsection{Inward investment examples}

Table 9 present five examples of employers who have either, moved into the City, or who are existing indigenous employers who have chosen to consolidate to premises within Nottingham rather than relocating elsewhere. Table 10 represents 5 examples of employers who have moved out of Nottingham. It should be stressed that this is the sum of all examples known to NCC (November 2014).

Table 9 shows that for 3 out of the 5 major investments, public transport (PT) connectivity was a major factor attracting these employers to locate in Nottingham. Two of these are located in the City Centre while the other is located in a business park within which a tram stop is now located as part of NET Phase 2. Interestingly, in one case, the WPL was a discussion point between Nottingham City Council and the employer, however, this issue was overcome by supporting the employer to minimise their liability for the WPL charge via reducing the demand for parking by providing workplace travel planning for staff. A further example indicates that public transport connectivity was a minor factor.

Table 9

Summary of examples of major inward investments.

\begin{tabular}{|c|c|c|c|c|}
\hline Type & $\begin{array}{l}\text { Improved } \\
\text { PT a factor }\end{array}$ & $\begin{array}{l}\text { Size of } \\
\text { employer }\end{array}$ & $\begin{array}{l}\text { Stated reasons for } \\
\text { decision }\end{array}$ & Notes \\
\hline New business to the City & Major & Medium & $\begin{array}{l}\text { Close to suppliers, } \\
\text { access to workforce, } \\
\text { PT connectivity }\end{array}$ & $\begin{array}{l}\text { Moved to Nottingham despite other options elsewhere in } \\
\text { Nottinghamshire, the UK, and Europe. Good PT access to site } \\
\text { was an important requirement thus car parking and the WPL } \\
\text { became a minor consideration }\end{array}$ \\
\hline New business to the City & Not at all & Large & $\begin{array}{l}\text { Close to suppliers, } \\
\text { close to customers }\end{array}$ & $\begin{array}{l}\text { Access to workforce and customers were key locational factors. } \\
\text { WPL was a factor, but was mitigated by discussion with NCC via } \\
\text { workplace travel planning support }\end{array}$ \\
\hline $\begin{array}{l}\text { Consolidation of indigenous } \\
\text { business }\end{array}$ & Major & Large & $\begin{array}{l}\text { Access to workforce, } \\
\text { PT connectivity }\end{array}$ & $\begin{array}{l}\text { Consolidated multiple Nottingham sites into City Centre } \\
\text { location, access for workforce by PT critical }\end{array}$ \\
\hline New business to the City & Minor & Medium & $\begin{array}{l}\text { Availability of suitable } \\
\text { property, PT } \\
\text { connectivity }\end{array}$ & $\begin{array}{l}\text { Company based on Business Park outside the City. The lease } \\
\text { expired due to redevelopment of their site. They identified a } \\
\text { premises located in the City which offered them proximity to } \\
\text { transport links, a suitable premises and some parking. They } \\
\text { have bought the building }\end{array}$ \\
\hline $\begin{array}{l}\text { Consolidation of existing } \\
\text { indigenous business }\end{array}$ & Major & Large & $\begin{array}{l}\text { Access to workforce, } \\
\text { PT connectivity }\end{array}$ & $\begin{array}{l}\text { Expansion project as company consolidates a number } \\
\text { properties into a large City building, ease of access for staff, } \\
\text { ease of operation with single site in City }\end{array}$ \\
\hline
\end{tabular}

Employer Size Key defined by number of jobs affected; 1-99 = Small, 100-199 Medium, Large 200+.

Table 10

Summary of examples of major decisions to relocate away from Nottingham (disinvestment).

\begin{tabular}{|c|c|c|c|}
\hline WPL factor & $\begin{array}{l}\text { Employment } \\
\text { implications }\end{array}$ & $\begin{array}{l}\text { Stated reasons } \\
\text { for decision }\end{array}$ & Notes \\
\hline Not at all & Large & $\begin{array}{l}\text { External pull } \\
\text { factors }\end{array}$ & Down-sizing and moving all manufacturing out of UK \\
\hline Not at all & Medium & $\begin{array}{l}\text { External pull } \\
\text { factors }\end{array}$ & $\begin{array}{l}\text { Consolidating multiple East Midland's sites into one site. Business was car based so access to } \\
\text { national and regional road network paramount, as was a central location }\end{array}$ \\
\hline Minor & Small & $\begin{array}{l}\text { External pull } \\
\text { factors WPL }\end{array}$ & $\begin{array}{l}\text { Consolidating into one site, current site not fit for purpose, WPL cited as a factor, half of staff } \\
\text { were not Nottinghamshire based }\end{array}$ \\
\hline Minor & Medium & $\begin{array}{l}\text { External pull } \\
\text { factors WPL }\end{array}$ & $\begin{array}{l}\text { Company growth triggered seeking alternative premises. WPL was mentioned as a factor for } \\
\text { the relocation outside of the City. However, greater weighting was given to the need for } \\
\text { suitable premises that could provide office and warehousing for products and such a site was } \\
\text { difficult to locate in Nottingham }\end{array}$ \\
\hline Not at all & Medium & $\begin{array}{l}\text { External pull } \\
\text { factors }\end{array}$ & $\begin{array}{l}\text { Relocation to office in another City with some redundancies. Triggered by Nottingham office } \\
\text { lease renewal and move to more flexible working arrangements }\end{array}$ \\
\hline
\end{tabular}

Employer Size Key defined by number of jobs affected; 1-99 = Small, 100-199 Medium, Large 200+. 
Table 10 shows 5 cases where businesses have moved out of Nottingham. Two cases cited the WPL as a contributory factor and in both cases this was considered as a minor factor. The principal drivers for both of these relocations were related to the suitability of the premises. In one case the lease expired on their current site which was no longer fit for purpose which combined with moving nearer to the majority of their workforce and consolidating their business into one site. The other business where the WPL was a minor factor moved out of their existing premises as a result of the growth of their business requiring larger premises which were found just outside Nottingham. The largest employer to leave was undergoing an international restructure related to a declining worldwide market and chose to move all its manufacturing away from the UK.

The above data supports the Theory of Change as it indicates that, while the cost of WPL is an extra cost to some businesses, it is such a small percentage of turnover that it plays a very small part in location decisions. Outweighing this it appears that businesses consider access to an efficient public transport network as an important factor when considering a potential location. Whilst cost is a significant factor when choosing a new location or considering remaining and reinvesting in a location, the above evidence suggests that the additional cost of WPL does not present a barrier for a company.

Table 11

Indicator trajectory and magnitude: as predicted by the ToC and Actual.

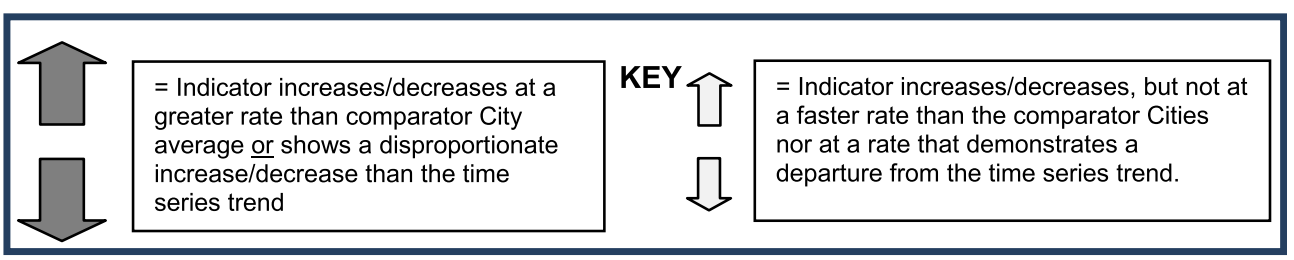

\begin{tabular}{|c|c|c|c|c|}
\hline \multirow[t]{2}{*}{ Indicator } & \multicolumn{2}{|c|}{$\begin{array}{l}\text { Change in indicator } 2010 / 11 \\
\text { to } 2013 / 14\end{array}$} & \multirow{2}{*}{$\begin{array}{l}\text { Movement Relative } \\
\text { to Comparator City } \\
\text { Average from } 2010\end{array}$} & \multirow[t]{2}{*}{ Comment } \\
\hline & Predicted & Actual & & \\
\hline $\begin{array}{l}\text { Jobs located } \\
\text { in } \\
\text { Nottingham }\end{array}$ & & & Greater & \multirow{2}{*}{$\begin{array}{l}\text { Job creation and economic } \\
\text { output is directly associated } \\
\text { with a buoyant inward } \\
\text { investment market. The ToC } \\
\text { predicts a strong growth in } \\
\text { these indicators as the WPL } \\
\text { package combines with C2, } \\
\text { an improving national } \\
\text { economic situation. }\end{array}$} \\
\hline $\begin{array}{l}\text { Economic } \\
\text { Output }\end{array}$ & & & $\begin{array}{l}\text { Greater - up to } 2012 . \\
2013 \text { data is provisional } \\
\text { but shows small } \\
\text { reduction in GVA in } \\
\text { Nottingham but not the } \\
\text { comparator Cities }\end{array}$ & \\
\hline $\begin{array}{l}\text { Business } \\
\text { Births and } \\
\text { Deaths }\end{array}$ & & & Less & $\begin{array}{l}\text { Only weakly linked to level of } \\
\text { inward investment as data is } \\
\text { dominated by smaller } \\
\text { business start-ups and } \\
\text { failures. }\end{array}$ \\
\hline $\begin{array}{l}\text { Commercial } \\
\text { property } \\
\text { market } \\
\text { activity }\end{array}$ & & & $\begin{array}{l}\text { No comparable data } \\
\text { available }\end{array}$ & $\begin{array}{l}\text { An increase would be the } \\
\text { predicted by the ToC, } \\
\text { however, there is a finite } \\
\text { amount of premises (C1) so } \\
\text { the magnitude could be } \\
\text { limited. }\end{array}$ \\
\hline $\begin{array}{l}\text { Inward } \\
\text { Investment } \\
\text { Enquiries } \\
\text { and } \\
\text { Successes }\end{array}$ & & & $\begin{array}{l}\text { No comparable data } \\
\text { available }\end{array}$ & $\begin{array}{l}\text { The ToC predicts a large } \\
\text { increase as the impact of the } \\
\text { WPL package combines with } \\
\mathrm{C} 2 \text {, an improving national } \\
\text { economic situation. }\end{array}$ \\
\hline $\begin{array}{l}\text { Case study } \\
\text { data }\end{array}$ & $\begin{array}{l}\text { Employers being } \\
\text { attracted to } \\
\text { Nottingham due } \\
\text { to good PT } \\
\text { connectivity. } \\
\text { Few, if any, de- } \\
\text { investors cite } \\
\text { WPL as a } \\
\text { significant factor }\end{array}$ & $\begin{array}{l}\text { AS } \\
\text { PREDICTED; } \\
3 \text { investors cite } \\
\text { PT as major } \\
\text { factor and } 1 \text { as } \\
\text { a minor. } \\
2 \text { de-investors } \\
\text { cite WPL as } \\
\text { minor factor }\end{array}$ & $\begin{array}{l}\text { No comparable data } \\
\text { available }\end{array}$ & $\begin{array}{l}\text { The ToC predicts that this } \\
\text { should show evidence that } \\
\text { the WPL is either, not a } \\
\text { factor in dis-investment } \\
\text { decisions, or a very minor } \\
\text { one, while there should be a } \\
\text { number of instances where } \\
\text { businesses cite good public } \\
\text { transport connectivity as a } \\
\text { major reason for their } \\
\text { location decision. }\end{array}$ \\
\hline
\end{tabular}


When new investors are comparing Nottingham to other comparable Cities, the fact that Nottingham remains cost competitive, despite the small additional cost of the WPL, means that it is still considered. Nottingham offers lower property and labour costs (the two largest operational costs for a business) when compared with cities such as Bristol, Milton Keynes and larger Cities such as Leeds and Manchester which ensures that it remains competitive.

\subsubsection{Synthesis for inward investment indicators}

The findings from the investment examples appear to agree with both the other two inward investment indicators, commercial property market activity and the level of inward investment enquires, which show significant increases in inward investment interest in Nottingham in the last two years. The purpose of the investment examples is to attribute the changes observed in the other two micro-economic indicators to the WPL package elements. Some attribution has been demonstrated in that 3 out of 5 investors quote public transport connectivity as an important factor in the decision to locate in Nottingham. However, this observation is caveated in that it is based on a small number of case studies.

\section{Discussion}

Table 11 summarises the movement of the indicators and compares this to what is predicted by stakeholder consensus within the Theory of Change. The magnitude of each change is merely described as large, small or none, any attempt to provide a numerical figure would be spurious as there is not enough existing data from similar interventions to accurately predict this. A similar approach is taken for differential change to the comparator Cities for the macro-economic indicators.

Table 11 is helpful when considering the triangulation of the indicators in order to gain an overall understanding of the effectiveness of the WPL Package in meeting the economic objective. The number of jobs located in Nottingham, the number of investment enquiries, the level of activity in the commercial property market and crucially the case study evidence all agree with the proposed Theory of Change in terms of both magnitude and direction.

However, the provisional 2013 GVA data for Nottingham and the net balance of Business Births and Deaths are more ambiguous and cannot at this stage help to strengthen the ToC. However, as this data is either provisional or less directly linked to the WPL than the other indicators, they are not, at this stage in the evaluation, a major cause for concern with regards to the veracity of the ToC. However, they must be continued to be monitored and further research is required to understand a continuing trend counter to the ToC.

The ToC highlights an expectation that in the long run efficiency savings in the wider economy will be derived from agglomeration effects, increased labour force productivity and other general equilibrium effects brought about by an enhanced public transport system (Hensher et al. (2012), Lakshmanan, 2011). It is possible that the strong performance from the inward investment indicators is the first sign of these effects kicking in, however it may be some time before these effects can be demonstrated as at this point in time the major transport infrastructure improvements have not had time to fully activate these mechanisms.

\section{Conclusions}

Considering the data and analysis presented in the previous section it can be seen to what extent the data shows that the indicators are moving in the direction and magnitude that would be expected according to the ToC and thus, how well the Nottingham WPL Package is achieving the intended economic impacts.

The number of jobs based in Nottingham has seen strong and sustained growth and suggests that Nottingham has fared better than average when compared to other comparator Cities. This supports the veracity of the ToC and, despite ambiguous performance on economic output and net business registrations, it is concluded that there is no observable negative effect on overall macro-economic performance associated with the introduction of the WPL.

The level of commercial property market activity and the number of inward investment enquires and subsequent successes have shown strong growth in 2012/13 and 2013/14 and also support the veracity of the ToC. The investment examples collated so far suggest that the WPL is a relatively minor consideration when businesses make investment decisions, while the availability of good connectivity to public transport has been a strong attractor to at least three major inward investments in this period. Where the WPL has been cited as a factor by a potential investor it has been shown that they can be persuaded that the cost can be mitigated by the business support measures put in place by Nottingham City Council and funded by the WPL. The above conclusion fits well with the Theory of Change that has been developed for this objective, but more case study data is required to confirm these observations.

When all the economic indicators are triangulated it is possible to conclude that:

- There is strong evidence that the WPL is having no significant negative impact on inward investment. This is supported by case study evidence that suggests that the WPL plays a very small role in business location decisions.

- The strong growth in employment combined with a positive movement in the inward investment specific indicators suggests that Nottingham is relatively attractive to potential investors. There is positive evidence from case studies of 5 major inward investments that the public transport improvement components of the WPL package are playing a role in this. 
- Overall, while not yet conclusive, the evidence suggests that, on the balance of probability, the WPL package is making good progress towards this objective with the majority of chosen indicators moving in the direction and magnitude that would be expected given the agreed Theory of Change.

The economic performance of a large City and relating this to any single intervention is always difficult as is demonstrated by the lack of literature pertaining to successful evaluations. The use of pure statistical techniques is dogged by a complex web of dependent variables while no single independent variable can truly be said to demonstrate success.

The approach taken in this paper demonstrates a way of tackling this problem that is open to most practitioners and, while the authors do not pretend that it will be possible to prove a position beyond all reasonable doubt or within some pre-determined statistical margin, it is suggested that a reasonable balance of probability case has been presented by intelligent consideration of the available data which most stakeholders can agree is valid.

\section{References}

Arauzo-Carod, J.M., Liviano-Solis, D., Manjon-Antolin, M., 2010. Empirical studies in industrial location: an assessment of their methods and results. J. Regional Sci. 50 (3), 685-711.

Anderstig, C., Berglund, S., Eliasson, J., Andersson, M., 2016. Congestion charges and labour market imperfections. J. Transport Econ. Policy 50 (2), 113-131 (19).

Banister, D., Thurstain-Goodwin, M., 2011. Quantification of the non-transport benefits resulting from rail investment. J. Transp. Geogr. 19 (2011), 212-223.

Blamey, A., Mackenzie, M., 2005. The practice and the theory: lessons from the application of theories of change approach. Evaluation 11, $151-168$.

Blamey, A., Mackenzie, M., 2007. Theories of change and realistic evaluation: peas in a pod or apples and oranges? Evaluation 13, 439-455.

Bhat, C., Chandra, R., Peleti, R., Singh, P., 2014. A spatial multivariate count model for firm location decisions. J. Regional Sci. 54, 462-502.

Burchell, J., Ison, S., 2012, Employers attitudes to the workplace parking levy: a case study of Nottingham, UK. In: 92nd Annual Meeting of the Transportation Research Board, TRB, 09-0249, 12 Washington DC, USA, January 2012.

Button, K.J., Leitham, S., McQuaid, R.W., Nelson, J.D., 1995. Transport and industrial and commercial location. Ann. Reg. Sci. 29 (2), $189-206$.

Button, K., 2010. Transport Economics. Edward Elgar Publishing.

Combes, P., Mayer, T., Thisse, J.F., 2008. Economic Geography: The Integration of Regions and Nations. Princeton University Press, Princeton, NJ.

Connell, J.P., Kubisch, A.C., 1998. Applying a theory of change approach to the evaluation of comprehensive community initiatives: progress, prospects, and problems. In: Connell, J.P., Kubisch, A.C., Schorr, L.B., Weiss, C.H. (Eds.), New Approaches to Evaluating Community Initiatives, vol. 2, Theory, Measurement and Analysis. Washington, DC: Aspen Institute.

Core Cities, Passenger Transport Executive Group and Yorkshire Forward, 2006. How does transport influence business investment in the city regions [online], Report into research carried out by GVA Grimley sponsored by Core Cities, Passenger Transport Executive Group and Yorkshire Forward, available at: <http://www.pteg.net/system/files/general-docs/GVA_transport_and_business_200611.pdf> (accessed 29/05/2015).

Dale, S.J., Frost, M.W., Gooding, J., Ison, S.G., Warren, P., 2014. A case study of the introduction of a workplace parking levy in Nottingham. In: Ison, S.G., Mulley, C. (Ed.), Transport and Sustainability; Parking; vol 5; Ashgate, ISBN: 978-1-78350-919-5 (Chapter 15).

Department for Transport, 2013. [draft] Best Practice Guidance for planning the Fuller Evaluations of Local Authority Major Schemes, unpublished.

East Midlands Development Agency (EMDA), 2007. Economic Costs of Congestion in the East Midlands. Atkins for the East Midland Development Agency, Nottingham.

Eliasson, J., 2009. A cost-benefit analysis of the Stockholm congestion charging system. Transport Res. Part A: Policy Pract. 43 (4), $468-480$.

Figueiredo, O., Guimaraes, P., Woodward, D., 2002. Home-field advantage: location decisions of Portuguese entrepreneurs. J. Urban Econ. 52 (2), $341-361$. Graham, D.J., 2007. Agglomeration, productivity and transport investment. J. Transport Econ. Policy 41 (Part 3), $317-343$.

Hayter, R., 1997. The Dynamics of Industrial Location: The Factory, the Firm, and the Production System. Wiley, Chichester, pp. 61-89.

Hensher, D.A., Truong, T.P., Mulley, C., Ellison, R., 2012. Assessing the wider economy impacts of transport infrastructure investment with an illustrative application to the North-West Rail Link project in Sydney, Australia. J. Transport Geogr. 2 (2012), $292-305$.

HM Treasury, 2011. The Magenta Book, online <http://www.hm-treasury.gov.uk/data_magentabook_index.htm> (accessed 29/05/2015).

Lakshmanan, T.R., 2011. The broader economic consequences of transport infrastructure investments. J. Transp. Geogr. 1 (2011), $1-12$.

Lambert Smith Hampton, 2014. What occupiers want: Office Market Review 2014 available online at www.lsh.co.uk (accessed on 29/05/15).

Leape, J., 2006. The London congestion charge. J. Econ. Perspect. 20 (4), 157-176.

Losch, A., 1954. The Economics of Location. Yale University Press, New haven, CT.

Nottingham City Council (NCC), 2005. Workplace Parking Levy Economic Impact, PwC for Nottingham City Council, Nottingham: available on request from Nottingham City Council www.nottingahmcity.gov.uk (accessed 29/05/2015).

Nottingham City Council (NCC), 2008. Workplace Parking Levy Business Case [online], Nottingham: Nottingham City Council, April 2008 Available at: $<$ http://open.nottinghamcity.gov.uk/comm/download3.asp?dltype=inline\&filename=33021/WPLBusCase.doc> (accessed 29/05/2015).

Nottingham City Council (NCC), 2015. Nottingham Local Transport Plan 2011 to 2026. [Online] Nottingham: Nottingham City Council, online. <www. nottinghaminsight.org.uk/d/94332> (accessed on 29/05/15).

Nottingham Post, 2012. Levy may see us move on after 27 years, claims depot manager, [online] Nottingham: Nottingham Post, available on line at <http:// www.thisisnottingham.co.uk/Levy-27-years-claims-depot-manager/story-15678012-detail/story.html> (accessed on 29/05/15).

Pawson, R., Tilley, N., 1997. Realist Evaluation. Sage, London.

Pawson, R., Tilley, N., 2004. Realist Evaluation, Paper for the British Cabinet Office, online <http://www.communitymatters.com.au/RE_chapter.pdf> (accessed 29/05/2015).

Quddus, M.A., Carmel, A., Bell, M.G., 2007. The impact of the congestion charge on retail: the London experience. J. Transport Econ. Policy (JTEP) 41 (1), 113133.

Richardson, E., 2010. Extracting Maximum Benefit From Parking Policy - 10 Years' Experience in Perth, Australia. European Transport Conference 2010,38th ed., Glasgow, Scotland, UK October 2010, London: The Association for European Transport.

Smyth, A., Christodoulou, G., Newman, P., 2010. Smart Connections: The essential role of transport for borderless business, London: Invest Thames Gateway Available online at <http://i-dmc.co.uk/resources/documents/ITG_TL_006_spreads.pdf> (accessed on 09/05/15).

Transport for London, 2008. Central London Congestion Charge: Impacts Monitoring Sixth Annual Report: July 2008, [online] City of London: Transport For London Available at <https://www.tfl.gov.uk/cdn/static/cms/documents/central-london-congestion-charging-impacts-monitoring-sixth-annual-report. pdf $>$ (accessed 29/05/2015).

Venables, A.J., 2016. Incorporating Wider Econmic Impacts within Cost Benefit Appraisal Evaluating Urban Transport Improvements; International Transport Forum round table discussion - Quantifying the Socio-econmic Benefits of Transport, Discussion Paper 2016.05.

Weber, A., 1929. Theory of the Location of Industry. University of Chicago Press, Chicago, IL. 